\title{
Finding common ground: how the development of theory in public health research can bring us together
}

\author{
Karl Gauffin ${ }^{1} \cdot$ Andrea Dunlavy $^{1}$
}

Published online: 26 August 2019

(c) The Author(s) 2019

\begin{abstract}
Within the past few decades, the academic discipline of public health has taken root in universities around the world. As a young and multidisciplinary field with a dual-research/practice focus and a tradition that emphasises method development, the use of theory in public health research has often been neglected. In this article, we argue that explicit utilisation of theory is crucial to further the development of public health as an academic discipline. By examining three core areas of academic activity at universities - education, research and public outreach-we illustrate the role theory plays in establishing public health as an independent research discipline. We discuss the importance and benefits of including theoretical reasoning in teaching, research articles and communication with non-academic audiences. We also highlight the role of postgraduate students and junior researchers who, thanks to a combination of experience and receptiveness, play an important role in developing public health theory. We believe that a key to a successful process of establishing public health as an academic discipline lies in the development of a transdisciplinary approach to the research subject. This will equip public health researchers with appropriate tools to take on the public health challenges of the future.
\end{abstract}

Keywords Theory $\cdot$ Transdisciplinary $\cdot$ Paradigm $\cdot$ Public health $\cdot$ Research . Education 


\section{Introduction}

\section{General contribution of theory to public health as an academic discipline}

Theory is as a fundamental backbone of all academic disciplines. As public health grows and develops as an academic discipline at universities, we may consider some general purposes or functions of theory in public health research.

In a diverse and fragmented discipline such as public health, a theoretical framework can provide researchers with a common paradigm to frame our scientific approach and to create a shared point of departure. A shared paradigm, in the words of Thomas Kuhn, implies a joint commitment "to the same rules and standards for scientific practice" (Kuhn 1970). A paradigm can be thought of as a worldview or a thought pattern, and is something far more overarching than other theoretical concepts, such as models or hypotheses (Carpiano and Daley 2006; Krieger et al. 2012). As shown in Fig. 1, our research paradigm also serves as a determinant of our ontological and epistemological positions, and as such, it not only defines the way we collect knowledge about the world, but also our understanding of the world itself. Our methodology, on the other hand, determines how we go about to produce valid knowledge reflecting our ontological and epistemological positions. Finally, our methods are the tools of data collection, selected in accordance with our methodology (Comber 2012; Creswell 2003; Bevir 2008). Public health as an academic discipline has traditionally focused on the use and development of research methods. However, in order for public health to fully benefit from theory, increased attention to the other, broader sets of concepts constituting our paradigm could help us to shape and define our field of research (Weed 1999; Frohlich et al. 2004; Comber 2012).

This consideration of other theoretical concepts inherent within a paradigm also serves to promote theory's function as a lens through which we examine our empirical findings.

Fig. 1 Concepts inherent in a research paradigm

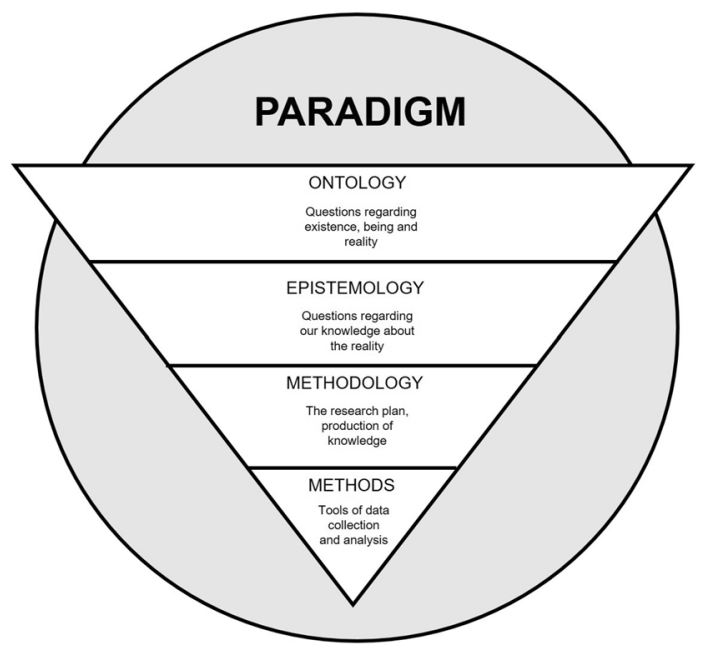


The famous words of Immanuel Kant in his Critique of Pure Reason illuminate this function: "Thoughts without content are empty, intuitions without concepts are blind". This quote illustrates the interdependent relationship between theory and empirical material, but also hints that our blindness can be remedied with theoretical glasses or, in other words, a lens. Theory's functionality as a lens allows us to see clearly and to make sense of our findings. Through theory, we are able to see the distinct objects of our research behind the numbers and the data. The lens metaphor is also useful to point out that, just as lenses come in different colours, different theories provide different meanings to the same empirical observations (Krieger 2008).

Finally, theory also serves as a means of generating new knowledge and furthering public health's development as an academic discipline. This function of theory may be illustrated by a quote from Hannah Arendt in her well-known book The Human Condition: "it is not likely that our technically conditioned world could survive, let alone develop further, if we ever succeeded in convincing ourselves that man is primarily a practical being" (Arendt 1958). Arendt points to the importance of theoretical guidance when taking steps into the unknown. In a world in which theory and philosophy have become the "handmaidens" of science and technology, we lack a guiding light that not only provides a way forward, but also points to researchers' moral and political responsibilities. The ethical obligations of public health researchers are particularly important, as the investigation of sensitive topics is often part of our research agenda. For example, when researchers study health inequalities between different racial and gender groups, it is imperative that they access the theoretical body of work on the health effects of racism, sexism and other systems of oppression (Jones 2000; Krieger 2016). If we instead attribute our results to unfounded and unexamined assertions of genetic or biological differences, we risk reproducing racist, sexist and colonial fantasies, and give these the legitimacy of academic research. Hannah Arendt's work serves as a reminder of our responsibility as researchers. Her writings often make the connection between theory and ethics evident by pointing to the vulnerability of human kind and the fragility of the world. Devoting much of her thought to the crimes of Nazi-Germany, Arendt reminds us that inhumane actions can and have been done in the name of public health promotion. We need theory and ethics to prevent violations of individual integrity for the sake of research.

\section{Today's public health discipline}

Despite these essential scientific functions that theory provides, there are a number of challenges to the development and integration of theory in public health research, some of which arise in part due to characteristics of the discipline itself.

First, compared to many other research fields, public health is a relatively young academic discipline, which developed out of public administrative actions and efforts in the early twentieth century to improve population health. As such, the theoretical foundations of modern public health are grounded in those of related disciplines, including biomedical science, public administration and behavioural 
psychology (Potvin et al. 2005; Porter 1999). This in turn implies a paucity of foundational theories that are unique to public health sciences.

Second, public health has a dual-core focus on research and practice, which entails a disciplinary divide between those whose primary focus is explaining and understanding the world, and those who aim to change it (Connelly 2005). This affects our understanding of what theory is, what theory should be used for and which theory is necessary and appropriate for our research or practice purposes.

Third, the strong focus on research methods within the public health sciences not only distracts from other essential theoretical components within a paradigm, but also shifts our attention away from the populations we study and onto methodological tools and techniques. As such, rather than being problem based, the discipline has increasingly become more methods based, which can result in research methods defining research hypotheses rather than utilisation of appropriate methods to test these hypotheses (Kaplan 2004; Muntaner 1999). The primacy of methods can also lead to the routine inclusion of variables within our statistical models, without sufficient theoretical support to justify or explain why such variables are included (Kaplan 2004; Muntaner 1999)

Finally, the multidisciplinary nature of public health can impact how theory is developed, used and understood. Multidisciplinary fields can be defined as those which add and combine knowledge, ideas or methods from two or more disciplines (Stokols et al. 2013). This has the potential to enrich the discipline as a whole, provided that researchers understand each other. Yet the use of diverse and partly unfamiliar definitions, concepts and methods within a multidisciplinary field may lead to mutual confusion among researchers with differing academic backgrounds or specialities. Such partial or casual understandings can lead to "conceptual looseness" (Kaplan 2004) of key theoretical constructs, which not only inhibits the integration of knowledge from different fields, but can also lead to a sub-par "reproduction" of knowledge that has been more thoroughly investigated in other related research disciplines. The inherent multidisciplinarity of public health serves to reify the existing sub-disciplinary divides and niches. In addition, it could impair the development of foundational public health sciences theory, as well as the integration of different theoretical approaches and subsequent creation of new frameworks, hypotheses and research strategies.

In contrast to multidisciplinary fields, interdisciplinary research can be characterised by the integration of different perspectives, concepts and theories and methods from two or more disciplines. Transdisciplinarity, however, not only integrates different approaches, theories and methods, but actually leads to the creation of new conceptual frameworks, hypotheses and research strategies, which are necessary to solidify public health as an independent academic discipline (Stokols et al. 2013). It also transcends pre-existing disciplinary boundaries and translates research findings into practical solutions, which addresses the multidisciplinary and dual research/ practice nature of public health (see Fig. 2).

Given these four features of our academic discipline (it is young, both practice and research oriented, methods based and multidisciplinary), proper use and development of theory in public health research has been limited. In this paper, we suggest that one reason behind this major challenge is that the field of public health has 


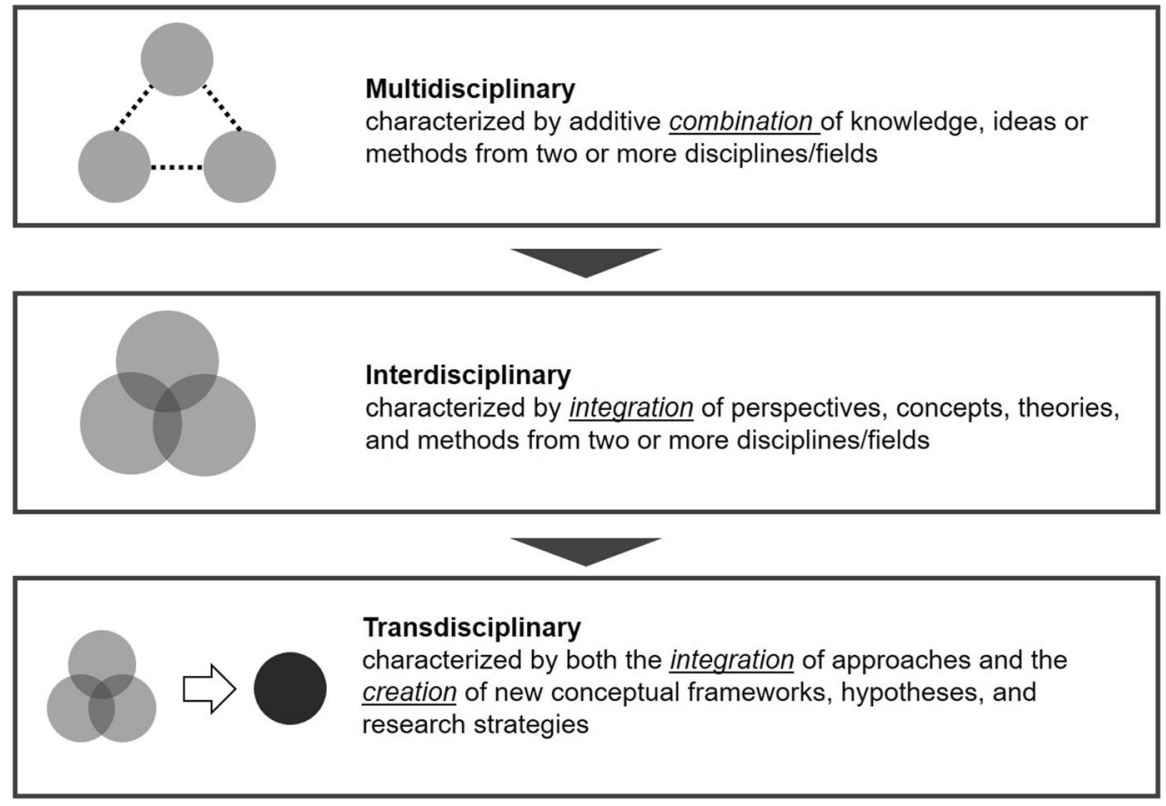

Fig. 2 Multi-, inter- and transdisciplinarity. Based on definitions by Stokols et al. (2013)

not yet reached transdisciplinarity. Aiming for transdisciplinarity, we argue that it is actually the use and integration of theory that will truly establish public health as an independent academic discipline in and of itself. This will in turn allow us to create new conceptual frameworks, hypotheses and research strategies.

\section{Main body}

In the main body of this paper, we will discuss the prerequisites for integrating theory into public health research as well as its potential effects. How can we integrate theory into public health research and how will this integration serve the development of the discipline in and of itself? We will discuss these questions with reference to the three major focal areas of universities: education, research and public outreach.

\section{Education}

One indication that an academic discipline is becoming more independent could arguably be the extent to which it is taught at the undergraduate level in university programmes. This idea relies on the logic that undergraduate students enter the tertiary education system with a more or less a clean slate. They are not at the university to deepen their expertise in a research field or to develop existing skills, but are in need of an introduction to empirical work within a topic, and to the basics of 
academic inquiry. For this, they require a theoretical framework for future studies. The lack of theory within public health research could possibly be an obstacle for undergraduate students to acquire the tools needed to conduct academic research, but this is not necessarily true everywhere. Ideally, undergraduate students are part of an environment that has devoted some time to the establishment of public health as an academic discipline.

Postgraduate students are at a stage in their academic careers where they may play a central role in theory development. Unlike undergraduate students, they are not inexperienced or unfamiliar with academic inquiry, but often they are still in search of a theoretical point of departure for their empirical work. This combination of experience and receptiveness makes them valuable assets for the development of the discipline and for lowering the thresholds for undergraduate students interested in public health. Traditionally, postgraduate students of public health come from other disciplines, such as sociology, medicine, nursing, biology, political science or psychology. Yet in the course of their postgraduate studies, students develop shared frameworks, terminologies and research approaches adapted to public health goals. This is not to deny that public health will continue to be a heterogeneous field. Just as there are vast differences in the academic approaches of sociologists, political scientists and psychologists of different schools, public health researchers are also influenced by a number of different traditions. While embracing this heterogeneity, the transition from multi- to transdisciplinarity will ideally take place in a successful postgraduate programme. The students enter the field from different academic positions and exit as public health scholars.

Finally, researchers who also have teaching duties have an excellent opportunity to promote students' familiarity with public health theory. Referencing and explicitly lecturing about theory is both informative and signals to the students that theory is a vital component of public health research. Public health education study directors have further possibilities to integrate theory lectures and seminars into public health programmes.

\section{Research}

Even as we lack foundational public health theory, all public health research disciplines, to some degree, are nonetheless informed by theory. Theories of causation and error inform the methodological base of the discipline and help us to analyse our data. Theories of health behaviour, health education, programme planning and community engagement inform the practice base, and help us to improve health. Epidemiological theories inform the research base, and help us to explain patterns of population health, linking the social with the medical (Kaplan 2004; Krieger 2001, 2011).

Reframing and tweaking our research practices can help us to overcome the challenges of theory use and development in public health today. Although a young discipline, we have already witnessed the expansion of the field throughout the twentieth century, and we see the beginnings of its institutional entrenchment via increased public health education programmes at several levels. One way that researchers 
can continue to encourage the theoretical development of our discipline and a shift towards transdisciplinarity is to be more explicit and precise when describing theoretical terminologies and constructs. Levels of understanding and familiarity with different theories, frameworks and models will certainly vary among researchers, but this is completely acceptable and can even be beneficial if we are explicit and consistent with our use of these terms. Over time, this consistency should entail a broader understanding of central theoretical ideas and concepts that comprise the backbone of our discipline as a whole.

Still, we are all bound by the word limits of scientific journals, which can be as low as 2500 words; however, more and more journals are now calling for the explicit inclusion of theory within our papers. This can help us to prioritize theory in our work, and enable us to communicate our theoretical orientations to the reader. As research practice is often directly informed by our empirical findings, this explicit communication is vital to ensuring that we are effectively communicating between the two hearts of our discipline, and easing the disciplinary divide between research and practice.

Researchers also need to keep this theoretical reframing in mind when considering our choice of research methods. The increasing dominance of methods within public health research has grown in tandem with increased access to large data sources, including biological data, and improved technologies and software to analyse our data. To a certain degree, these developments alone have encouraged multidisciplinarity, as vast amounts of data and methods of analysis have increased the ease of and opportunities for collaboration. However, we need to exercise caution, and ensure that new methodological technologies have a "conceptual grounding" that is uniquely public health (Keyes and Galea 2016). This can help us to move towards a transdisciplinary public health, which comprises multiple perspectives in our approach to and understanding of population health, but also solidifies our common conceptual understandings as researchers. This will enable us to use our research methods and theories in tandem, as equal partners, no longer relegating theory as a handmaiden of science.

\section{Public outreach}

Public health is a discipline that responds to the needs of society. To completely dissolve the division between public health as research and public health as practice is neither possible nor desirable. Rather, the dual nature of public health is an important reason for researchers to devote time to public outreach and communication of their research to the world within and outside of academia. As academic researchers, a large part of this work is centred on three main activities: (1) writing proposals for research funding, (2) publishing our results in scientific journals and (3) interaction with relevant actors to share our work and inform policy and practice.

Most, if not all, researchers are familiar with the grant writing duties associated with our work. We write applications in response to funding opportunities that are both broad and narrow in scope. However, funding agencies have the ability to promote theory building and transdisciplinarity by requiring researchers to describe 
their theoretical points of departure in their funding applications and promoting calls for funding that explicitly request the formation of transdisciplinary research groups (see Vogel et al. 2014 for an example of such an initiative). Researchers can express their interest in such initiatives to funding agencies in different ways, but may also submit applications that are transdisciplinary in nature even when the funding mechanism does not call for it.

When submitting research articles to journals that do not strictly dictate the components of the article structure, researchers could try to include a section on theory. Editors of scientific journals could also promote this by suggesting or even requiring that the authors pay explicit attention to the theoretical foundations of their work, as is often done with the description of research methods as a required component of scientific abstracts. In this way, theory will become more accessible and familiar to readers.

When communicating with a non-academic audience, theory can likewise be used as a tool to make research more accessible. The methodological details of our work can be overwhelming to those unfamiliar with our research methods, and a well-communicated theoretical idea may serve as a more approachable platform from which we can present our work. This is particularly important when thinking about the moral, ethical and political commitments that many researchers in public health sciences feel obliged to. Whereas medical doctors may swear the Hippocratic Oath to uphold specific ethical standards in their practice, public health researchers do not make any equivalent pledges or sworn declarations. Yet, in a world in which the most severe public health hazards include politically amenable phenomena, such as poverty, precarious labour, educational inequalities, gender and racial discrimination and the climate crisis, it is of utter importance that public health researchers understand, and communicate with, the world in which they live. Greer et al. (2017) write: "if public health is the field that diagnoses and strives to cure social ills, then understanding political causes and cures for health problems should be an intrinsic part of the field". In order for this understanding to have impact on the political causes of public health, researchers are well advised to sharpen their communication with actors outside of academia. Basing this communication on a theoretically grounded and empirically correct foundation is an important step in making a valid contribution to a better and healthier world.

\section{Conclusion}

The development of an academic discipline is characterised by reciprocal relationships. In this article, we have discussed the development of public health research as a result of the dynamics between the empirical findings, theoretical frameworks and increasing transdisciplinarity of public health. We have devoted particular attention to the relationship between transdisciplinarity and theory. We have argued that they go hand in hand, fuelling the development of one another. This process not only strengthens the scientific rigour of our discipline and makes it more accessible to the public, but it also allows us to solidify our research area and create a new, independent, scientific field of study. 
Similar to other young disciplines, public health research has long been a melting pot of different ideas and research traditions. Adding the strong orientation to public health practice and focus on method development, this article has discussed a number of challenges to the development of public health theory. We maintain, however, that theory development and the interrelated move towards transdisciplinarity are vital to take public health research to the next level. Like most other academic disciplines, public health research responds to the needs and interests of the real world. Our research needs to continuously deliver clear and determined responses to emerging public health problems. We believe that a broad and heterogeneous, but theoretically grounded academic discipline of public health is key in addressing the population health challenges that lie ahead.

Open Access This article is distributed under the terms of the Creative Commons Attribution 4.0 International License (http://creativecommons.org/licenses/by/4.0/), which permits unrestricted use, distribution, and reproduction in any medium, provided you give appropriate credit to the original author(s) and the source, provide a link to the Creative Commons license, and indicate if changes were made.

\section{References}

Arendt, H. 1958. The human condition. London: University Press Chicago.

Bevir, M. 2008. Meta-methodology: Clearing the Underbrush. In The Oxford handbook for political methodology, ed. J. Box-Steffensmeier, H. Brady, and D. Collier. Oxford: Oxford University Press.

Carpiano, R., and D. Daley. 2006. A guide and glossary on postpositivist theory building for population health. Journal of Epidemiology and Community Health 60: 564-570.

Comber, C. 2012. The role of theory in research. Theoretical and conceptual frameworks. Leicester: University of Leicester.

Connelly, J. 2005. More public health theory please-But make it adequate. Journal of Public Health 27: 315.

Creswell, J.W. 2003. Research design. Qualitative, quantitative and mixed methods approaches. Thousand Oaks, CA: Sage Publications Inc.

Frohlich, K.L., E. Mykhalovskiy, F. Miller, and M. Daniel. 2004. Advancing the population health agenda: Encouraging the integration of social theory into population health research and practice. Canadian Journal of Public Health 95: 392-395.

Greer, S.L., M. Bekker, E. de Leeuw, M. Wismar, J.-K. Helderman, S. Ribeiro, and D. Stuckler. 2017. Policy, politics and public health. European Journal of Public Health 27: 40-43.

Jones, C.P. 2000. Levels of racism: A theoretic framework and a gardener's tale. American Journal of Public Health 90: 1212-1215.

Kaplan, G.A. 2004. What's wrong with social epidemiology, and how can we make it better? Epidemiologic Reviews 26: 124-135.

Keyes, K.M., and S. Galea. 2016. Setting the agenda for a new discipline: Population health science. American Journal of Public Health 106: 633-634.

Krieger, N. 2001. Theories for social epidemiology in the 21st century: An ecosocial perspective. International Journal of Epidemiology 30: 668-677.

Krieger, N. 2008. Ladders, pyramids and champagne: The iconography of health inequities. Journal of Epidemiology and Community Health 62: 1098-1104.

Krieger, N. 2011. Epidemiology and the people's health: Theory and context. Oxford: Oxford University Press.

Krieger, N. 2016. Living and dying at the crossroads: Racism, embodiment, and why theory is essential for a public health of consequence. American Journal of Public Health 106: 832-833.

Krieger, N., D. Dorling, and G. McCartney. 2012. Mapping injustice, visualizing equity: Why theory, metaphors and images matter in tackling inequalities. Public Health 126: 256-258.

Kuhn, T.S. 1970. The structure of scientific revolutions. Chicago: University of Chicago Press. 
Muntaner, C. 1999. Invited commentary: Social mechanisms, race, and social epidemiology. American Journal of Epidemiology, 150, 121-126; discussion 127-128.

Porter, D. 1999. Health, civilization and the state. A history of public health form ancient to modern times. London: Routledge.

Potvin, L., S. Gendron, A. Bilodeau, and P. Chabot. 2005. Integrating social theory into public health practice. American Journal of Public Health 95: 591-595.

Stokols, D., K.L. Hall, and A.L. Vogel. 2013. Transdisciplinary public health: Core characteristics, definitions, and strategies for success. In Transdisciplinary public health: Research, methods, and practice, ed. D. Haire-Joshu and T.D. Mcbride. San Francisco: Jossey-Bass Publishers.

Vogel, A.L., B.A. Stipelman, K.L. Hall, L. Nebeling, D. Stokols, and D. Spruijt-Metz. 2014. Pioneering the transdisciplinary team science approach: Lessons learned from national cancer institute grantees. Journal of Translational Medicine \& Epidemiology 2: 1027.

Weed, D.L. 1999. Towards a philosophy of public health. Journal of Epidemiology and Community Health 53: 99-104.

Publisher's Note Springer Nature remains neutral with regard to jurisdictional claims in published maps and institutional affiliations.

Karl Gauffin is a post-doctoral researcher at the Centre for Health Equity Studies within the Department of Public Health Sciences at Stockholm University. His research interests include work conditions and health including precarious work, theory development in public health research and migration and health.

Andrea Dunlavy is a post-doctoral researcher at the Centre for Health Equity Studies within the Department of Public Health Sciences. She is currently working as a project manager within the FORTEfunded research programme Studies of Migration and the Social Determinants of Health (SMASH) and as a researcher within the large Nordic research project Coming of Age in Exile (CAGE), funded by NordForsk. 